\title{
AS IMAGENS DO OUTRO EM O ESPLENDOR DE PORTUGAL, DE ANTÓNIO LOBO ANTUNES
}

Cid Ottoni Bylaardt UFC

\begin{abstract}
RES U M O
Este trabalho pretende empreender um estudo das imagens do estrangeiro, focalizado como "o outro", nas relações entre as vozes e os corpos do romance O esplendor de Portugal, de António Lobo Antunes. Essa análise comparatista propõe conceber uma imagem literária sobre o estrangeiro como elemento cultural que remete à sociedade, uma imagologie que lida com a literarização e a socialização da imagística.
\end{abstract}

\section{PALAVRAS - CHAVE}

Imagens. $O$ outro. Estrangeiro. Imagologie.

Sob a aura da reminiscência, as vozes do passado se presentificam nos corpos dos desterrados, multiplicando imagens da alteridade. As dolorosas recordações não reúnem os fragmentos pretéritos; ao contrário, contribuem para dispersá-los cada vez mais, até a separação definitiva e a morte. A coleção de cacos em permanente disjunção decreta o desencontro definitivo dos corpos solitários, abandonados, inapetentes, segregados, abastardados, abjetos.

A escrita de $O$ esplendor de Portugal, de António Lobo Antunes, se produz nas falas de uma mãe e seus três filhos: Isilda, Carlos, Rui e Clarisse. Isilda descende de uma família de colonos portugueses em Angola, proprietários de uma fazenda de algodão e girassol. No recrudescimento da guerra que sucedeu à independência de Angola, Isilda, então viúva, envia os filhos de volta a Portugal em 1977, e tenta preservar suas terras e sua produção, ao lado de duas criadas negras, Maria da Boa Morte e Josélia. Os relatos que compõem a narrativa se situam entre a colonização e a descolonização, e se centram nos olhares de uns sobre os outros: os colonos, os pretos, os portugueses e outros conquistadores.

O romance tem como epígrafe uma citação do hino nacional português, que contém a expressão que dá título ao livro:

Heróis do mar, nobre povo,

Nação valente e imortal,

levantai hoje de novo

o esplendor de Portugal!

Dentre as brumas da memória

ó Pátria sente-se a voz 
dos teus egrégios avós

que te há-de levar à vitória.

Às armas, às armas,

sobre a terra e sobre o mar!

Às armas, às armas,

pela Pátria lutar!

Contra os canhões marchar, marchar.

Esse significante vazio é o discurso do senhor, a fala da hegemonia que ecoa na África, recontextualizada parodisticamente no período pós-colonial. As vozes da narrativa fazem contraponto com a epígrafe, numa espécie de inversão da alegoria nacional, produzindo o discurso do histérico, que interroga em vão a não-verdade do senhor. Em O esplendor de Portugal, "dentre as brumas da memória" ecoam as vozes escatológicas da impossibilidade, do sem-sentido, da ausência de projetos. Os "egrégios avós" não passam de aventureiros que buscam poder em seus pretos, mas terminam sendo também os pretos dos outros. O significante vitória perde completamente seu significado nessa relação agonística entre europeus e africanos.

Nosso objeto de investigação aqui são os olhares com que o personagem Carlos, nessa multidão de perdidos, tenta expressar sua (in)compreensão do mundo, a partir da tentativa de reconstituição espaciotemporal de sua inserção no processo de colonização em Angola e de sua descolonização na segunda metade do século XX. Incluem-se aí as representações do outro, as imagens do estrangeiro e do estranho nas relações entre as vozes e os corpos, considerando o enfoque do estereótipo do racismo e a revelação do espaço da ideologia daquele que olha, e como ele é olhado. Os olhares de Carlos e sobre Carlos, na narrativa, ricocheteiam incessantemente, sem ter onde pousar, perdendose na impossibilidade de seu ser como mestiço desterritorializado, cujo discurso não tem o direito de significar.

Esses jogos de representação contemplam também o fenômeno da colonização dentro da colonização, representado pela metáfora da dominação na relação hierárquica dos olhares entre brancos e pretos, conforme a fala de Isilda, mãe de Carlos:

O meu pai costumava explicar que aquilo que tínhamos vindo procurar na África não era dinheiro nem poder mas pretos sem dinheiro e sem poder algum que nos dessem a ilusão do dinheiro e do poder que de fato ainda que o tivéssemos não tínhamos por não sermos mais que tolerados, aceitos com desprezo em Portugal, olhados como olhávamos os bailundos que trabalhavam para nós e portanto de certo modo éramos os pretos dos outros da mesma forma que os pretos possuíam os seus pretos e estes os seus pretos ainda em degraus sucessivos descendo ao fundo da miséria, aleijados, leprosos, escravos de escravos, cães. ${ }^{1}$

Os filhos de Isilda falam de Lisboa; o dia da enunciação é 24 de dezembro de 1995, véspera de natal; Isilda fala de Angola, em momentos diferentes, que se iniciam em 24 de julho de 1978 e vão até 24 de dezembro de 1995, quando o tempo de Angola encontra o tempo de Portugal e sela a definitiva separação: a mãe morre e os filhos se desencontram definitivamente. Na primeira parte do romance, alternam-se os discursos de Carlos e da

${ }^{1}$ ANTUNES. O esplendor de Portugal, p. 243. A partir daqui, as referências ao romance O esplendor de Portugal serão indicadas apenas com o número da página entre parênteses. 
mãe; na segunda parte, as falas de Rui e da mãe; e na terceira, alternam-se as vozes de Clarisse e de Isilda. Ao todo, a mãe profere quinze discursos, e cada um dos filhos tem cinco falas.

Carlos tem a palavra inicial. Em seu apartamento da Ajuda, ele espera a visita dos irmãos para a ceia de natal, após tê-los expulsado de casa quinze anos antes. O horizonte da memória de Carlos abre-se pela janela da cozinha do pequeno apartamento da Ajuda, que traz as "brumas da memória" misturadas ao cigarro de Lena, sua esposa "mussequeira". Carlos diz à mulher que havia convidado os irmãos para passarem com eles a noite de Natal. Em meio às baforadas e à voz de Lena, os guindastes e barcos que se seguem aos últimos telhados da Ajuda (topônimo que encerra uma alusão óbvia), e os morros de Almada, a ponte sobre o Tejo, a estátua de Cristo "a bater sozinha acima da bruma o desamparo das asas" (p. 9) desaparecem para ceder lugar às lembranças de Angola, de seu namoro com Lena, do ataque da tropa da Unita, da casa da mãe, dos criados.

O personagem, sabe-se depois, não é filho de Isilda, mas de seu marido com uma negra empregada do refeitório da Cotonang, companhia estrangeira de algodão. A primeira consideração de Carlos sobre a independência de Angola revela sua repulsa à atual condição de seus compatriotas negros, rejeitando a "Angola cheia de pretos na fortaleza, no palácio do Governo e nas cabanas da ilha refastelados ao sol, a julgaremse nós" (p. 10). A recusa de Angola concretiza-se na recusa de ler as cartas da mãe, que se amontoam numa gaveta, sem sequer serem abertas, "cartas iguais a bichos malcheirosos, mortos” (p. 10). Da mesma forma, recusa a irmã Clarisse, que ele expulsou de casa por "mau comportamento", o irmão Rui, internado por ele em uma espécie de clínica e a mulher Lena, de quem planeja separar-se.

Apesar das reiteradas recusas, a janela da cozinha teima em repor as imagens de Angola, em bruscas mudanças espaciais: "fiquei sozinho na cozinha a ouvir o zumbido do frigorífico e a olhar os morros da Almada, a olhar a fazenda do postigo do jipe à medida que nos afastávamos pelos buracos da picada" (p. 12). A metáfora da janela como abertura de cena faz o personagem reviver também o que Bhabha chama o "duplo demoníaco" da metrópole: a guerra, as injustiças, as atrocidades, a discriminação. A presença pós-colonial de Carlos em Lisboa articula a narrativa da diferença cultural que nega o narcisismo do "esplendor de Portugal" que o hino insiste em convocar o "nobre povo" para levantar.

Carlos ocupa uma posição curiosa na narrativa: ele é um mestiço, filho de uma angolana negra e de pai branco. Sua pátria não é a Angola dos negros nem a Europa dos brancos. Assim, ele carrega em si as diferenças que procura estabelecer em relação às outras personagens, e que não consegue representar nem para si mesmo:

chamavam um Carlos que era eu em elas não era eu nem era eu em eu, era um outro da mesma forma que se lhes respondia não era eu quem respondia era o eu deles que falava, o eu em eu calava-se em mim e portanto sabiam apenas do Carlos delas, não sabiam de mim e eu permanecia um estranho, um eu que era dois, o deles e o meu, e o meu por ser meu não era, então dizia como eles diziam Carlos

${ }^{2}$ BHABHA. O local da cultura, p. 237. 
$[\ldots]$

até a palavra Carlos esvaziada de nexo não significar nada salvo um som semelhante ao dos ramos das mangueiras ou aos suspiros sem perguntas dos setters no seu sono, até a palavra Carlos se tornar uma pele que se larga, não o eco de um eco mas um corpo sem vida fora da vida deles, e então podia fechar os olhos, partir do escuro deles, das preocupações deles e dissolver o meu eu em mim à medida que o relógio de parede, mudando de ritmo, intrigava os pavões, eu na Ajuda à entrada do quarto (p. 114).

Percebe-se no trecho acima a confusão identitária de Carlos, a estranheza e a irrepresentabilidade de seu nome, um significante sem significado, um corpo sem vida, porque ele é a história irrepresentável da dominação do europeu sobre o africano, e produto dúbio dos extremos. Na ausência de um modelo cultural que lhe permita representar a imagem do outro, Carlos não consegue definir sua posição em relação aos demais personagens, colocando-se à deriva em sua condição de esquizóide.

O mestiço tenta organizar sua confusão apegando-se à metáfora do relógio de parede em sua infância: enquanto ele continuasse a bater, a vida na África estaria garantida, "a casa e a minha família e Angola inteira" (p. 62), tudo estaria funcionando. O relógio é, assim, o elemento a que Carlos se aferra para tentar ordenar sua hibridização conflituosa, que, entretanto, não se resolve, permanecendo, como o pêndulo, em constante oscilação. Já em Lisboa, ele pensa em sua separação de Lena, que tornaria maior o apartamento, "despido dos ouropéis de Angola, máscaras, colares, estatuetas, rinocerontes” (p. 98). A presença da África, então, abandonaria o lar, e sua ausência seria preenchida pelo vazio, contribuindo para afastá-lo da memória de Angola: "(quero lá saber de Angola, não me falem de Angola, deixem-me em paz com Angola há séculos que Angola palavra de honra acabou para mim)” (p. 98).

Angola, no entanto, teima em não deixá-lo em paz. Numa de suas reflexões, Carlos afirma que "se me separasse da Lena, comprava um vaso e sementes de azálea para me lembrar de Angola" (p. 93).

Em meio a toda essa ambigüidade e hibridização, os sentimentos de Carlos são predominantemente negativos. É também ambivalente seu olhar dirigido ao pai, o branco deslocado entre os pretos, o bêbado que se dissolve no álcool diante da insolubilidade da vida. A mãe, que ele detesta e despreza, é vista igualmente de maneira dúbia, "a minha mãe da manhã, mais velha e pobre e baixa e feia do que a minha mãe da noite” (p. 62).

Os mitos brancos da mesma forma não encontram ressonância na busca vã de identidade de Carlos: é impossível para ele figurar o Papai Noel deslizando pelo território africano "numa espira de neve a trinta e oito graus à sombra", e descer por uma chaminé que em sua casa terminava no fogão, "arriscando o Papai Noel a fazer companhia ao pato e ao arroz no forno, e além disso não era capaz de conceber como um cavalheiro gordo caberia num tubo estreito e sujo" (p. 35). Tal questionamento do mito por parte de uma criança revela uma total falta de consideração do mestiço angolano-português à mais significativa tradição cristã européia. O mito questionado reaparece quando Carlos, já adulto, lança um olhar de desprezo ao "pinheiro ridículo espetado no vaso com a estrela de lantejoulas no topo, enfeitado como uma cinqüentona triste de grinaldas” (p. 47).

Na narrativa, o Natal é um pretexto para Carlos reencontrar os irmãos que ele mesmo expulsara de casa havia 15 anos. Em seu penúltimo discurso, sufocado pela indiferença dos convidados, que não compareceram, ele começa a desmanchar o cenário natalício 
que ele mesmo havia arrumado, demonstrando a intenção de se desfazer de tudo, "a transportar a caixa, os presentes, o pinheiro e o vaso para o patamar derramando o Natal pelo elevador" (p. 96). O derrame metonímico do mito amplia-se até a negação total das relações e das encenações familiares:

fiz não sei quantas viagens, cada vez mais ensopado, do vestíbulo ao contêiner e do contêiner ao vestíbulo, primeiro o vaso e as pedras do vaso, depois as ampolas e os presentes e por último o estorvo do pinheiro até o Natal

que bom

se sumir da minha vida, os meus irmãos que léria, a família que conversa fiada, os jantarinhos comovidos que mentira, enquanto as varetas e o pano do guarda-chuva se torciam ao vento e um bêbedo se dirigia a mim em guinadas felizes (p. 97).

O mito do nascimento do Deus-menino é uma narrativa reguladora da ordem cristã, o vaticínio da harmonia universal. No romance, a insistência na data de 24 de dezembro de 1995, véspera de Natal, tem o efeito de destruir as esperanças de união: o encontro das duas datas ao final decretam a morte de Isilda e a separação definitiva dos demais. A irônica citação da expressão latina "FINIS LAUS DEO" (p. 381) arremata a narrativa da impossibilidade, desautorizando o mito cristão. Ao mesmo tempo, ela expressa o alívio de chegar ao final essa história de desgraças.

A ambigüidade essencial de Carlos nasce na relação dele mesmo com sua própria raça, sua mestiçagem não-resolvida. Aos sete ou oito anos, ele descobre que há algo diferente em si mesmo pela maneira como a negra Maria da Boa Morte o trata; ao invés de chamar-lhe "menino", como aos irmãos, ela o trata por "tu", tratamento reservado aos íntimos, aos iguais, até que a terrível frase é pronunciada: “- Tu és preto” (p. 90). Maria da Boa Morte profere o interdito, denunciado por Clarisse, o que propicia à negra uma temporada de prisão e maus-tratos.

A revelação reveste-se de ambivalência nas reflexões do menino. De um lado, ser preto significaria poder andar descalço sem ser molestado pelos adultos, correr mais depressa, ter mais força. Prevalece, contudo, o lado negativo de ser preto num mundo dominado por brancos:

preto como a Josélia, o Fernando, o Damião, os contratados, o capataz ia chegar à cozinha e mandar-me trabalhar na safra, tiravam-me o quarto, os brinquedos, o meu lugar à mesa, comia pirão e peixe seco, bebia cerveja numa cantina, dormia numa esteira, curava icterícia com tubérculos, não acreditava em Deus (p. 92).

Segundo Stuart Hall, o termo raça é "uma construção política e social. É a categoria discursiva em torno da qual se organiza um sistema de poder socioeconômico, de exploração e exclusão - ou seja, o racismo". ${ }^{3}$ Segundo ele, o racismo procura assim uma lógica discursiva num certo "efeito de naturalização", em que as causas genéticas e biológicas legitimam a exclusão justificando as diferenças sociais e culturais. Carlos tem lábios de branco, nariz de branco, cabelos de branco, cor de branco, mas sua raça seria denunciada pela cor do sangue e por "um vestígio no formato das unhas que nem um médico se lembraria de examinar” (p. 86). A diferença racial é praticamente imperceptível,

${ }^{3}$ HALL. Da diáspora, p. 69. 
as diferenças culturais não existem entre ele e os de sua família, por motivos óbvios, mas há um estigma que delata sua condição espúria e que o faz sentir-se desprezado por todos. Afinal, o "efeito de naturalização" não passa de um eufemismo que a escrita de Lobo Antunes parodia no disfemismo que torna pretos os brancos de Angola em relação aos brancos de Portugal: "éramos os pretos dos outros da mesma forma que os pretos possuíam os seus pretos e estes os seus pretos ainda em degraus sucessivos” (p. 243).

Em suas falas, Isilda afirma que Carlos não gosta dos irmãos nem da mulher, mas gosta da cozinheira negra Maria da Boa Morte. Ela afirma que gosta do filho mestiço, que não o despreza, e que comprar o apartamento em Lisboa em nome dele é uma demonstração de seu apreço; na visão de Carlos, entretanto, as reduzidas dimensões do apartamento são uma prova de que a mãe e o pai o detestam.

O epilético Rui monta em seu discurso a imagem de Carlos que ele percebe nas atitudes dos outros: Maria da Boa Morte, a cozinheira, tem uma visível predileção pelo menino mestiço, e o privilegia com iguarias feitas às escondidas; a avó, por outro lado, tem profunda vergonha do neto bastardo e miscigenado, e o trata como os brancos aos bailundos; Clarisse, a irmã, tem consciência da condição de diferente de Carlos, e indaga-lhe de maneira provocativa por que a avó se envergonha dele. Rui registra ainda o choro de Carlos por ser desprezado pelos brancos. Rui declara que no fundo sente pena de Carlos e de sua solidão, "sempre trancado num apartamento da Ajuda olhando o rio por um intervalo de cortinas a pensar em Angola, esperando que a Maria da Boa Morte o chame" (p. 182). O Rui criança percebe a dessemelhança do Carlos de maneira condenatória, acusando-o de ter sido comprado pela mãe como se compravam vassouras de piaçava e cestos, e para confirmar suas impressões, pergunta à irmã se o Carlos gosta de comer peixe seco e pirão (como os negros angolanos), se ele não seria então irmão dos leprosos (os seres mais asquerosos na escala de abjeções).

Também Isilda reporta as imagens dos filhos pelos outros e por ela mesma: a mãe, avó dos meninos, sente profundo desprezo pelos netos: um mestiço, uma prostituta e um epilético, segundo ela.

Independentemente de serem mestiços ou não, os colonos de origem portuguesa são também vistos como seres inferiores e condenados na imagem que Isilda faz de si mesma e de sua família, citando as palavras do pai:

conforme o meu pai costumava explicar

olhavam para nós como criaturas primitivas e violentas que aceitavam o degredo em Angola a fim de cumprirem condenações obscuras longe da família, de uma aldeia qualquer sobre penhascos de onde vínhamos, habitando no meio dos pretos e quase como eles, reproduzindonos como eles na palha, nos dejetos para formarmos uma raça detestável e híbrida (p. 244).

O pai de Isilda, no relato dela, tinha perfeita consciência de que colonizar a África não continha nenhuma atitude de grandeza ou de elevação do esplendor de Portugal por parte deles. Tudo não passava de interesses em jogo, cujos vencedores eram os portugueses da Europa, que enriqueciam com suas percentagens e impostos, até que um dia os americanos, ou russos, ou franceses, ou ingleses, ou todos eles armariam os negros para expulsar os portugueses, "em nome da liberdade que não teriam nunca" (p. 244), e assim os angolanos seriam mais eficientemente explorados do que houveram sido pelos portugueses. 
O pai de Isilda faz uma previsão funesta sobre a sorte dos portugueses durante a descolonização:

os que não engordarem o caju esquartejados nos trilhos e nos degraus das casas tornarão a Portugal expulsos através dos angolanos pelos americanos, os russos, os franceses, os ingleses que não nos aceitam aqui para chegarmos a Lisboa onde nos não aceitam também, carambolando-nos de secretaria em secretaria e ministério em ministério por uma pensão do Estado, despachando-nos como fardos de quarto de aluguel em quarto de aluguel nos subúrbios da cidade, nós e os mulatos e os indianos e inclusive os pretos que vieram conosco por submissão ou terror, não por estima, não por respeito, não julgues um segundo sequer que por estima ou respeito, não acredites na estima e no respeito sobretudo quando se assemelham a estima e a respeito (p. 244).

Nesse texto Isilda reporta à análise que Amadeu faz das condições dos colonizadores e dos colonizados, bem como dos descolonizadores e dos descolonizados, e todas as conclusões convergem para a impossibilidade, a desesperança, a disjunção. Não há perspectiva de convivência, de negociação decente, de relação bilateral entre quaisquer das partes. Para Amadeu, é inútil procurar o caminho de volta à Europa; ele sugere então à filha que permaneça em Angola, mesmo que ela envie os filhos de volta à pátria que não é deles. É imperativo que ela fique, e é o que ela faz à custa da própria vida, num marcha inútil contra os canhões.

O esplendor de Portugal é, assim, uma epopéia às avessas, em que conceitos como conquista, esplendor, grandeza são aviltados nos encontros impossíveis. As memórias que compõem as imagens do outro e do estrangeiro são fragmentárias, estilhaçadas, entrelaçadas; os seres impiedosos se ferem cruelmente uns aos outros, despidos de valores humanos, os quais invariavelmente se expressam por intermédio das coisas e dos elementos da natureza. Por trás de todas essas representações falidas de registros humanos trágicos, percebe-se um outro olhar, que contém muito de riso, mas um riso de esgar, de irrisão sobre a insolubilidade da condição humana.

Essa escrita de Lobo Antunes ultrapassa a condição de denúncia, de questionamento da noção de esplendor, de discurso nacional alegórico às avessas, para negar o funcionamento da própria idéia de colonização/descolonização, reduzindo-a a uma atitude desprovida de sentido humano, a uma escatologia sem redenção, condição de eterna perturbação das relações entre os seres.

\section{A}

\section{A B STRACT}

This paper intends to study the images of the foreigner, focused as "the other", in the relations between the voices and the bodies in the novel $O$ esplendor de Portugal, by António Lobo Antunes. This comparative analysis proposes to conceive a literary image about the foreigner as a cultural element related to society, an imagologie that deals with literarization and socialization of imagistics.

\section{KEYWORDS}

Images. The other. Foreigner. Imagologie. 


\section{REFERÊNCIAS}

ANTUNES, António Lobo. O esplendor de Portugal. Rio de Janeiro: Rocco, 1999.

BHABHA, Homi K. O local da cultura. Belo Horizonte: Ed. UFMG, 1998.

HALL, Stuart. Da diáspora: identidades e mediações culturais. Belo Horizonte: Ed. UFMG, 2003. 